\title{
Stationarity-Inducing Techniques in Small Open Economy Models with Collateral Constraints
}

\section{Vasiliki Dimakopoulou ${ }^{1}$ iD}

Accepted: 30 October 2020 / Published online: 18 November 2020

(C) The Author(s) 2020

\begin{abstract}
I show that the alternative stationarity-inducing techniques that have been used to "close" the standard small open economy model (like an endogenous discount factor and a debt-elastic interest rate premium) have different implications for the equilibrium dynamics once I add a commonly-used collateral-type financial constraint. Given this non-equivalence, my results further show that a small open economy model with a credit constraint that embodies an endogenous discount factor is superior to the debt-elastic interest rate model when one tries to match this kind of models to the data.
\end{abstract}

Keywords Small open economy $\cdot$ Stationarity $\cdot$ Borrowing constraints

JEL Classification E44 · F41

\section{Introduction}

As is well known, one has to add a "friction" to make the equilibrium dynamics of a standard small open economy (SOE) model stationary and so get a well-defined solution. Two particularly popular frictions have been an endogenous discount factor (EDF) in agents' optimization problem and a debt-elastic interest rate (DEIR) at which domestic agents borrow from abroad. ${ }^{1}$ But, then, as is also well known, if one uses an appropriate parameterization, the choice of the friction, and hence of the model, is trivial because they predict identical steady states and transition dynamics

\footnotetext{
${ }^{1}$ See Schmitt-Grohé and Uribe (2003) and Uribe and Schmitt-Grohé (2017). See also e.g. Uribe and Yue (2006), Mendoza (1991, 2002, 2010), Korinek and Mendoza (2014) and many others.

$\triangle$ Vasiliki Dimakopoulou

vasiliki-eirini.dimakopoulou@warwick.ac.uk

1 Department of Economics, University of Warwick, Coventry, CV4 7AL, England
} 
at business-cycle frequencies. ${ }^{2}$ What I show in this short paper is that, once I add a collateral constraint, this equivalence does not hold any more and so the choice between an EDF model and a DEIR model ceases to be a trivial issue.

I build upon the baseline small open economy model. I first add an EDF and a DEIR mechanism as in the above literature and, in turn, I also add a simple financial constraint, as in e.g. Mendoza (2002), which is also used by the literature on sudden stops. ${ }^{3}$ The latter means that domestic agents cannot borrow more than a fraction of their assets from the world capital market so that, when it binds, it is like having a sudden stop. To demonstrate the different implications of the two mechanisms, I first solve and evaluate the two models (i.e. the EDF and the DEIR) by comparing their steady state solutions both when the collateral constraint is binding and when it is not binding. Then, I solve and evaluate their dynamics. In particular, I assume that both models happen to be at the financially unconstrained steady state equilibrium (which is the same across models) and are then hit by a temporary adverse shock to TFP. Again, I compare the two models with and without the collateral constraint, where, in the case with, I use the methodology of Guerrieri and Iacoviello (2015) to allow for an occasionally binding collateral constraint.

My main results are as follows. The presence of the financial constraint breaks the equivalence between the EDF and the DEIR model and, more generally, breaks the celebrated result of being indifferent about the way of making the small open economy model stationary. This applies both to the steady state and to the transition. Given this, the comparison of the dynamics of the two models reveals that the EDF model predicts a slower recovery of a financially constrained economy from a temporary adverse TFP shock relatively to the DEIR model, which also helps to bring the small open economy model closer to the stylized facts.

Therefore, once I add collateral constraints, a proper mix of parameters is not enough to make these popular model specifications equivalent. The non-equivalence result arises from the Euler equations for foreign bonds and capital, in the sense that the introduction of the collateral constraint adds extra distortions also known as asset pricing wedges, which differ qualitatively across the EDF and the DEIR models. This is a reminiscent of the literature on balance sheet monetary policies. Once one adds financial frictions (like borrowing constraints, transaction costs, segmented markets, moral hazard, etc.) into Wallace (1981) baseline model, different balance-sheet monetary policies can lead to different asset pricing wedges and this allows these policies, and their mix, to affect the real economic activity (see Walsh 2017, chapter 11.5, for a review).

The rest of the paper is as follows. Section 2 presents the economic environment. Section 3 solves the model(s). The final section closes this short paper.

\footnotetext{
${ }^{2}$ See e.g. Schmitt-Grohé and Uribe (2003), Kim SH and Kose A (2003) and Uribe and Schmitt-Grohé (2017).

${ }^{3}$ On financial constraints and sudden stops see also e.g. Calvo (1998), Mendoza (2002), Korinek and Mendoza (2014) and Lorenzoni (2014).
} 


\section{A Small Open Economy Model}

I will augment a standard small open economy model with financial constraints. I will work in steps starting with the non-stationary model.

\subsection{Baseline Non-Stationary Model}

A small open economy is inhabited by a large number of identical infinitely lived households with preferences:

$$
E_{0} \sum_{t=0}^{\infty} \theta_{t} U\left(c_{t}, h_{t}\right)
$$

where $0<\theta_{t}<1$ is a time discount factor (defined below), $c_{t}$ is consumption and $h_{t}$ is hours of work. by:

The evolution of foreign debt, $d_{t}$, and physical capital, $k_{t+1}$, are given respectively

$$
\begin{gathered}
d_{t}=\left(1+r_{t-1}\right) d_{t-1}-y_{t}+c_{t}+i_{t}+\Phi\left(k_{t+1}-k_{t}\right) \\
k_{t+1}=(1-\delta) k_{t}+i_{t}
\end{gathered}
$$

where $y_{t}$ is output, $i_{t}$ is investment, $k_{t+1}$ is end-of-period capital, $d_{t}$ is end-of-period one-period risk-free international bonds, which pay the world real interest rate $r_{t}$ (defined below), the function $\Phi(\cdot)$ captures capital adjustment costs where $\Phi(0)=$ $\Phi^{\prime}(0)=0$ and $0<\delta<1$ is the capital depreciation rate. Notice that my notation is as close as possible to that in Schmitt-Grohé and Uribe (2003) (referred to as SGU) for reasons of comparability.

Output, $y_{t}$, is produced by a standard production function:

$$
y_{t}=A_{t} F\left(k_{t}, h_{t}\right)
$$

where $F\left(k_{t}, h_{t}\right)=k_{t}^{\alpha} h_{t}^{1-\alpha}, A_{t}$ is TFP (defined right below) and $0<\alpha<1$ is a parameter.

I assume a simple $A R(1)$ process for $A_{t}$ :

$$
\ln A_{t+1}=\rho \ln A_{t}+\varepsilon_{t+1}
$$

where $0<\rho<1$ is a persistence parameter and $\varepsilon_{t} \sim N I I D\left(0, \sigma_{\varepsilon}^{2}\right)$.

Households choose $\left\{c_{t}, h_{t}, i_{t}, k_{t+1}, d_{t}\right\}_{t=0}^{\infty}$ to maximize (1) subject to Eqs. 2-5. But, as is well known, this system is not stationary because the steady state of the model depends on initial conditions (see e.g. Schmitt-Grohé and Uribe 2003, and for more details Uribe and Schmitt-Grohé 2017).

\subsection{Making the Model Stationary}

As said in the Introduction, there are several ways of making the model stationary. Here, I will focus on the two most popular ones: an endogenous discount factor (EDF) and a debt-elastic country interest rate (DEIR). 

be: 4

In the EDF model, following SGU (Section 2), the discount factor is assumed to

$$
\begin{aligned}
& \theta_{t+1}=\beta\left(\widetilde{c}_{t}, \widetilde{h}_{t}\right) \theta_{t}, t \geq 0 \\
& \theta_{0}=1
\end{aligned}
$$

where $\beta_{\widetilde{c}}<0, \beta_{\widetilde{h}}>0$, and $\widetilde{c}_{t}$ and $\widetilde{h}_{t}$ denote the average per capita consumption and hours of work respectively, which the individual household takes as given. Notice that in this case the world interest rate can be treated as a parameter, i.e. $r_{t}=r$.

In the DEIR model, the world interest rate faced by domestic agents, $r_{t}$, is increasing in the aggregate level of foreign debt. Following SGU (Section 3), I assume: $:^{5}$

$$
r_{t}=r+\psi_{2}\left(e^{\tilde{d}_{t}-\bar{d}}-1\right)
$$

where $\tilde{d}_{t}$ denotes the aggregate level of foreign debt, which the individual household takes as given, and $\psi_{2}$ and $\bar{d}$ are parameters. Notice that in this case the discount factor can be treated as a parameter, i.e. $\theta_{t}=\beta^{t}$ where $0<\beta<1$.

\subsection{Adding a Simple Financial Constraint}

To the above standard setup, I add a financial constraint that limits households' borrowing ability to a fraction of their collateralized assets. Following e.g. Mendoza (2002), I have:

$$
d_{t} \leq \kappa k_{t+1}
$$

where $0<\kappa<1$ is a parameter. This constraint resembles a contract with imperfect enforcement, where foreign lenders cannot collect more than a fraction $\kappa$ of the value of debtor's assets. ${ }^{6}$ Under such a financial friction there exists a mismatch between the non-state contingent debt liabilities and the procyclical borrowing limit, which drives the financial amplification effects. ${ }^{7}$

In the context of the EDF model, the optimality conditions for capital and bonds are respectively:

$$
\begin{gathered}
\lambda_{t}\left(1+\Phi^{\prime}\left(k_{t+1}-k_{t}\right)\right)-\kappa \mu_{t}= \\
=\beta\left(\widetilde{c}_{t}, \widetilde{h}_{t}\right) E_{t} \lambda_{t+1}\left[A_{t+1} F_{k}\left(k_{t+1}, h_{t+1}\right)+1-\delta+\Phi^{\prime}\left(k_{t+2}-k_{t+1}\right)\right] \\
\lambda_{t}-\mu_{t}=\beta\left(\widetilde{c}_{t}, \widetilde{h}_{t}\right)(1+r) E_{t} \lambda_{t+1}
\end{gathered}
$$

where $\lambda_{t}$ and $\mu_{t}$ denote the non-negative Lagrange multipliers associated with the budget and the collateral constraint respectively. Details and the equilibrium system are in Appendix A.

\footnotetext{
${ }^{4}$ For a similar modeling of the discount factor see also Mendoza $(1991,2002,2010)$ and Kim SH and Kose A (2003).

${ }^{5}$ For a similar modeling of the foreign interest rate see also Philippopoulos et al. (2017).

${ }^{6}$ The collateral constraint is not derived as an optimal contract between borrowers and lenders, but imposed directly as in e.g. Kiyotaki and Moore (1997), Aiyagari SR and Gertler M (1999) and Mendoza (2002, 2010).

${ }^{7}$ For a discussion of the financial amplification mechanism see e.g. Mendoza (2010) and Korinek and Mendoza (2014).
} 
In the context of the DEIR model, the optimality conditions for capital and bonds are respectively:

$$
\begin{gathered}
\lambda_{t}\left(1+\Phi^{\prime}\left(k_{t+1}-k_{t}\right)\right)-\kappa \mu_{t}= \\
=\beta E_{t} \lambda_{t+1}\left[A_{t+1} F_{k}\left(k_{t+1}, h_{t+1}\right)+1-\delta+\Phi^{\prime}\left(k_{t+2}-k_{t+1}\right)\right] \\
\lambda_{t}-\mu_{t}=\beta\left(1+r_{t}\right) E_{t} \lambda_{t+1}
\end{gathered}
$$

Details and the equilibrium system are in Appendix B.

Inspection of the optimality conditions of the two models shows that the two mechanisms work through the Euler equation for foreign bonds. ${ }^{8}$ In the EDF model the Euler equation incorporates the level of consumption (Eq. (10)), whereas in the DEIR model the same equation incorporates the level of foreign debt (Eq. (12)). Absent credit frictions, the two models deliver identical solutions under an appropriate parameterization (see below). By contrast, when the economies are financially constrained, the positive shadow cost of relaxing the constraint reduces the discount factor in the EDF model, whereas it reduces external debt in the DEIR model. In particular, under a binding collateral constraint, the Euler equations (9) and (10) in the EDF model imply that a lower discount factor (or a lower degree of patience) leads to a fall in capital and output. On the other hand, the Euler equations (11) and (12) in the DEIR model imply that a lower external debt leads to lower interest rates and hence a crowding in of capital that stimulates output. Therefore, the non-equivalence result in the presence of binding collateral constraints has to do with the different ways in which the two mechanisms induce stationarity in the SOE model. This is a qualitative property that does not depend on the choice of structural parameters or functional forms. All this is confirmed below both in the steady state and the transition.

\section{Numerical Solutions and Main Results}

In this section, I perform a comparison of the EDF and DEIR models in the presence of collateral constraints. Put it differently, I examine whether the implications of binding credit constraints depend on the way stationarity is induced.

I will start by parameterizing the models. Then, to demonstrate the mechanisms behind the dynamics of two models, I will compare their steady state solutions as well as their transition dynamics as measured by impulse response functions (IRFs) of the main macroeconomic variables in response to a temporary adverse shock to TFP. To account for an occasionally binding collateral constraint along the transition, I will compute the models employing the toolkit proposed by Guerrieri and Iacoviello (2015). ${ }^{9}$

\footnotetext{
${ }^{8}$ See also the Introduction in SGU.

${ }^{9}$ Using the methodology by Guerrieri and Iacoviello (2015) I derive piecewise linear solutions of the two models. Since the solutions are linear, they fail to capture the precautionary savings motive induced by the risk of a binding collateral constraint in any future date.
} 
Table 1 Baseline parameter values

\begin{tabular}{lll}
\hline Parameter & Value & Description \\
\hline$\alpha$ & 0.32 & Share of capital \\
$\delta$ & 0.1 & Rate of capital depreciation \\
$\gamma$ & 2 & Elasticity of intertemporal substitution \\
$\beta$ & 0.96 & Discount factor in DEIR \\
$\omega$ & 1.455 & Disutility of labor \\
$\phi$ & 0.028 & Adjustment cost parameter of physical capital \\
$\psi_{1}$ & 0.11 & Elasticity of discount factor in EDF \\
$\psi_{2}$ & 0.000742 & Risk premium parameter in DEIR \\
$d$ & 0.7442 & Foreign debt threshold in DEIR \\
$r$ & 0.04 & Risk-free interest rate on foreign assets \\
$\kappa$ & 0.2 & Collateral constraint parameter \\
$\rho$ & 0.537 & Persistence of TFP \\
$\sigma_{\varepsilon}$ & 0.0134 & Standard deviation of TFP \\
\hline
\end{tabular}

\subsection{Parameter Values}

To help comparability, I set all structural parameters of the two models, other than the collateral constraint parameter $\kappa$, at the values used by SGU. Under this parameterization, and absent financial frictions, the two economies are identical. When I switch on the collateral constraint, the value of $\kappa$ is set at 0.2 as in Korinek and Mendoza (2014). With respect to the exogenous stochastic variable of TFP, I set $\rho=0.537$ and $\sigma_{\varepsilon}=0.0134$ as in Mendoza (2010) who studied the Mexican sudden stop event. Parameter values are listed in Table 1.

\subsection{Steady State Results}

Given the parameter values in Table 1, I solve for the steady state of the financially constrained and unconstrained regimes for both the EDF and the DEIR models. Solutions for the main macroeconomic variables, $\{y, c, h, i, k, d, t b / y, c a / y\}$, are reported in Table 2. ${ }^{10}$

When the financial constraint is not binding, the EDF and DEIR models deliver the same steady state solutions (see columns (1a) and (2a)); this is as in SGU. On the other hand, the solutions of the two models differ substantially when the financial constraint is binding (see columns (1b) and (2b)). As discussed at the very end of Section 2.3, the differences between the constrained regimes of the two models arise due to the fact that the Euler equation for foreign bonds determines the steady state value of the endogenous discount factor in the EDF model, whereas, in the DEIR model, the same equation determines the steady level of external debt. ${ }^{11}$ This

\footnotetext{
${ }^{10} \mathrm{As}$ in SGU, I define the current account-to-GDP ratio as $\frac{c a_{t}}{y_{t}}=\frac{d_{t-1}-d_{t}}{y_{t}}$,

${ }^{11}$ The qualitative predictions of the two models do not depend on the specific parameterization. Only the magnitude of relative changes is sensitive to parameterization. For example, the differences between the constrained regimes of the two models would be bigger under a higher value of the parameter $\psi_{1}$ in the EDF model, a lower value of the parameter $\bar{d}$ in the DEIR model, or a lower value of the collateral parameter $\kappa$.
} 
Table 2 Steady state solutions

\begin{tabular}{|c|c|c|c|c|c|}
\hline \multirow[b]{2}{*}{ Variable } & \multirow[b]{2}{*}{ Description } & \multicolumn{2}{|l|}{ EDF } & \multicolumn{2}{|l|}{ DEIR } \\
\hline & & $\begin{array}{l}\text { Unconstrained } \\
\text { (1a) }\end{array}$ & $\begin{array}{l}\text { Constrained } \\
\text { (1b) }\end{array}$ & $\begin{array}{l}\text { Unconstrained } \\
\text { (2a) }\end{array}$ & $\begin{array}{l}\text { Constrained } \\
\text { (2b) }\end{array}$ \\
\hline$y$ & Output & 1.4865 & 1.4841 & 1.4865 & 1.4866 \\
\hline$c$ & Consumption & 1.1170 & 1.1181 & 1.1170 & 1.1197 \\
\hline$h$ & Hours & 1.0074 & 1.0063 & 1.0074 & 1.0075 \\
\hline$i$ & Investment & 0.3398 & 0.3389 & 0.3398 & 0.3398 \\
\hline$k$ & Capital & 3.3977 & 3.3886 & 3.3977 & 3.3983 \\
\hline$d$ & Foreign debt & 0.7442 & 0.6777 & 0.7442 & 0.6797 \\
\hline$t b / y$ & $\begin{array}{l}\text { Trade balance as } \\
\text { a share of GDP }\end{array}$ & 0.02 & 0.0183 & 0.02 & 0.0183 \\
\hline $\mathrm{ca} / \mathrm{y}$ & $\begin{array}{l}\text { Current account } \\
\text { as a share of GDP }\end{array}$ & 0 & 0 & 0 & 0 \\
\hline
\end{tabular}

difference produces the macroeconomic results already discussed above and which are confirmed by the numerical solutions in Table 2. Namely, when the financial constraint binds, in the EDF model, households are less patient and the steady state values of output, investment and hours of work decrease relative to the unconstrained regime; in the DEIR model, these results are reversed.

\subsection{Transition Results}

In this section, I study the dynamic evolution of both models in response to a negative one-standard-deviation TFP shock. Specifically, I assume that the two economies start at the financially unconstrained steady state as solved above and are hit by a temporary adverse one-standard-deviation TFP shock. I use the methodology of Guerrieri and Iacoviello (2015) to capture the occasionally binding financial constraint after the departure from the unconstrained steady state solution.

\subsubsection{Baseline Simulations}

Without collateral constraints, the IRFs of the two models coincide (see Appendix C for details). ${ }^{12}$ On the other hand, inspection of the IRFs in Fig. 1 with collateral constraints, implies the following. Although, the transition paths in both models are qualitatively close indicating the typical costs of a negative TFP shock (namely a fall in output, capital and hours of work, being combined with debt-deleveraging and a short-lived improvement of the trade balance), the contractionary effects of this shock are quantitatively stronger and more persistent in the EDF model relative to the DEIR model. Specifically, in the EDF model, the external debt-to-GDP ratio decreases sharply and the fall in capital and investment is almost double as compared

\footnotetext{
${ }^{12}$ See also Schmitt-Grohé and Uribe (2003) and Kim SH and Kose A (2003).
} 


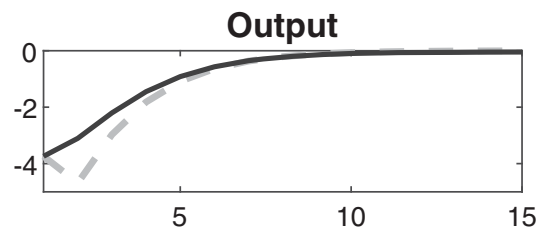

Investment
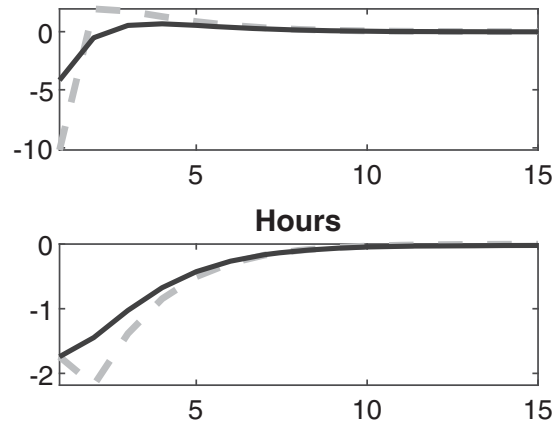

Current Account/GDP

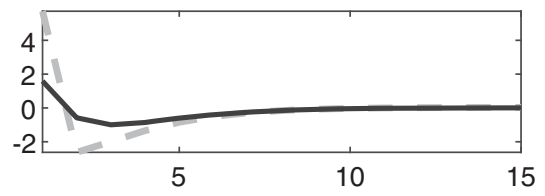

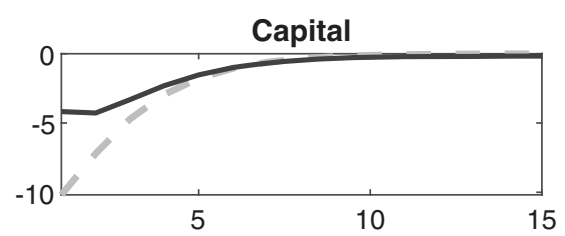

Consumption

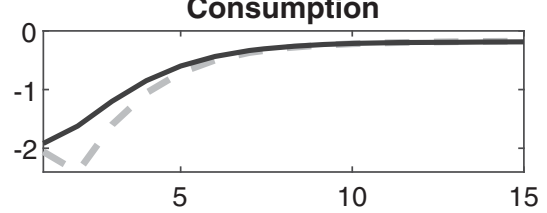

Trade Balance/GDP
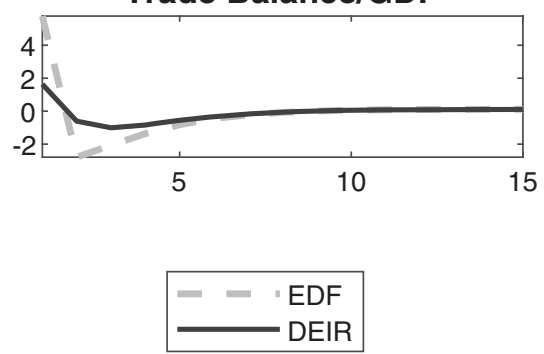

Fig. 1 Effects of a unit negative TFP shock in \% deviations from the steady state

to the respective dynamics in the DEIR model. In addition, in the EDF model, the lower discount factor induces a further reduction in output, consumption and hours of work as observed during sudden stops. On the other hand, in the DEIR model, the lower foreign interest rate faced by domestic households, which co-moves with the level of foreign debt, mitigates the adverse impact on investment and allows agents to better smooth out the adverse effects of the negative shock.

\subsubsection{Sensitivity Analysis}

The quantitative differences and implications of the two models depend on the parameterization employed. Specifically, while the EDF mechanism continues to induce higher amplification in the responses of the macro-aggregates to the negative TFP shock, the divergence between the IRFs of the two models is sensitive to changes in parameter values. To show this, I check the sensitivity of my results to changes in the value of the collateral constraint parameter, $\kappa$, other things equal. In particular, I compute the response functions to a negative one-standard-deviation TFP shock when the collateral constraint parameter is set at say 0.18 , instead of 0.2 which was the case in the baseline simulations. To better illustrate the divergence between the equilibrium dynamics of the two models, Fig. 2 plots the differences between the IRFs of the two models under the baseline parameterization (grey dotted line) and compare them against the case of a lower collateral threshold (black line). 

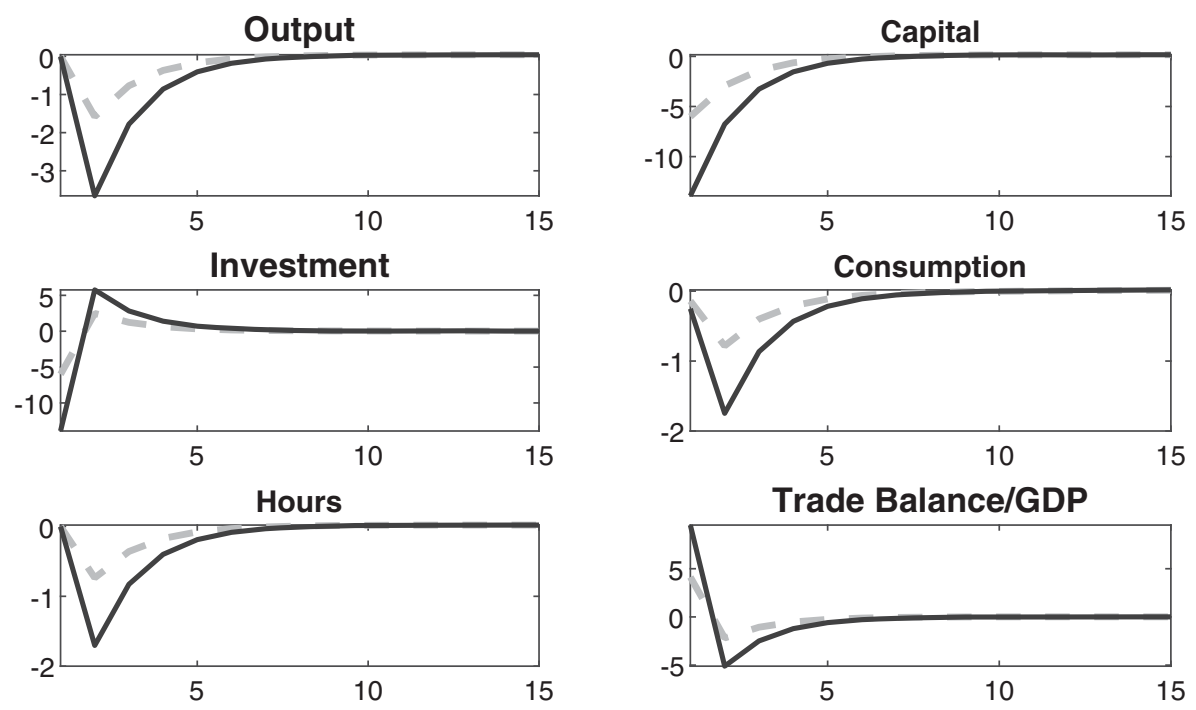

Trade Balance/GDP
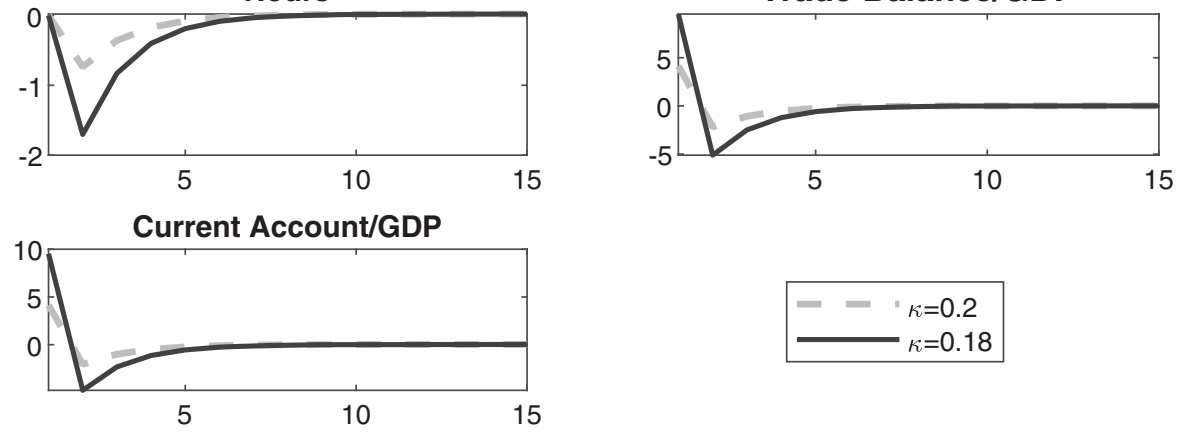

Fig. 2 Differences between the response functions of EDF and DEIR model to a unit negative TFP shock in $\%$ deviations from the steady state

Inspection of the differences between the transition paths of the two models in Fig. 2, implies that a tighter borrowing constraint results in a higher divergence between the dynamic responses of the two models to a negative TFP shock. In particular, when the economy is hit by a temporary adverse TFP shock, the contractionary effects are quantitatively bigger and last longer under the EDF channel, and these adverse effects become stonger as the value of $\kappa$ decreases meaning that the borrowing constraint gets tighter. ${ }^{13}$ Under both values of $\kappa$, the EDF mechanism seems to bring a financially constrained small open economy closer to the stylized facts.

\section{Conclusions}

In this paper, I added a collateral constraint to a small open economy model with an endogenous discount factor (EDF) or a debt-elastic country interest rate (DEIR). The main result is that the presence of financial constraints breaks the equivalence between the EDF and the DEIR model and, more generally, breaks the celebrated

\footnotetext{
${ }^{13}$ This result remains robust even under a different assumption on the borrowing limit, e.g. when it is a function of aggregate per capita consumption, like in Korinek and Mendoza (2014).
} 
result of being indifferent about the way of making the small open economy model stationary. The real economic activity is affected by which stationarity-inducing mechanism we use.

Acknowledgements I thank the editor, George S Tavlas, and the anonymous referee for constructive comments. I thank Apostolis Philippopoulos and Herakles Polemarchakis for comments and discussions. An early version of this paper has been presented at the International Conference on Macroeconomic Analysis and International Finance, the Annual Meeting of the Association of Southern European Economic Theorists and City University in London; I thank conference and seminar participants. Any errors are mine.

\section{Compliance with Ethical Standards}

Conflict of interests The author declares that she has no conflict of interest.

Open Access This article is licensed under a Creative Commons Attribution 4.0 International License, which permits use, sharing, adaptation, distribution and reproduction in any medium or format, as long as you give appropriate credit to the original author(s) and the source, provide a link to the Creative Commons licence, and indicate if changes were made. The images or other third party material in this article are included in the article's Creative Commons licence, unless indicated otherwise in a credit line to the material. If material is not included in the article's Creative Commons licence and your intended use is not permitted by statutory regulation or exceeds the permitted use, you will need to obtain permission directly from the copyright holder. To view a copy of this licence, visit http://creativecommonshorg/licenses/by/4.0/.

\section{Appendix A : A Model with an Endogenous Discount Factor}

\section{A.1 Functional Forms}

For my numerical solutions, I use the following functional forms for preferences as in SGU:

$$
\begin{gathered}
U\left(c_{t}, h_{t}\right)=\frac{\left(c_{t}-\omega^{-1} h_{t}^{\omega}\right)^{1-\gamma}-1}{1-\gamma} \\
\beta\left(\widetilde{c}_{t}, \widetilde{h}_{t}\right)=\left(1+\widetilde{c}_{t}-\omega^{-1} \widetilde{h}_{t}^{\omega}\right)^{-\psi_{1}} \\
\Phi\left(k_{t+1}-k_{t}\right)=\frac{\phi}{2}\left(k_{t+1}-k_{t}\right)^{2} ; \phi>0
\end{gathered}
$$

where $\gamma, \psi_{1}$ and $\phi$ are constant parameters.

\section{A.2 Household's Optimality Conditions}

Each domestic household chooses $\left\{c_{t}, h_{t}, i_{t}, k_{t+1}, d_{t}\right\}_{t=0}^{\infty}$, so as to maximize the utility function (1) subject to the Eqs. 2-5, the collateral constraint, Eq. 8, and the definition of the endogenous discount factor, Eq. 6, in the main text. The optimality conditions of the households are:

$$
\begin{gathered}
\lambda_{t}=U_{c}\left(c_{t}, h_{t}\right) \\
-U_{h}\left(c_{t}, h_{t}\right)=\lambda_{t} A_{t} F_{h}\left(k_{t}, h_{t}\right)
\end{gathered}
$$




$$
\begin{gathered}
\lambda_{t}\left(1+\Phi^{\prime}\left(k_{t+1}-k_{t}\right)\right)-\kappa \mu_{t}= \\
=\beta\left(\widetilde{c}_{t}, \widetilde{h}_{t}\right) E_{t} \lambda_{t+1}\left[A_{t+1} F_{k}\left(k_{t+1}, h_{t+1}\right)+1-\delta+\Phi^{\prime}\left(k_{t+2}-k_{t+1}\right)\right] \\
\lambda_{t}-\mu_{t}=\beta\left(\widetilde{c}_{t}, \widetilde{h}_{t}\right)(1+r) E_{t} \lambda_{t+1}
\end{gathered}
$$

\section{A.3 Macroeconomic Equilibrium}

I solve for a symmetric equilibrium in which all households are alike ex post. Thus, in equilibrium the individual and aggregate variables are identical:

$$
\begin{aligned}
c_{t} & =\widetilde{c}_{t} \\
h_{t} & =\widetilde{h}_{t}
\end{aligned}
$$

The equilibrium system can be summarized by the following 9 equations in 9 endogenous variables $\left\{c_{t}, h_{t}, i_{t}, k_{t+1}, d_{t}, \lambda_{t}, \mu_{t}, y_{t}, \theta_{t+1}\right\}_{t=0}^{\infty}$, given the exogenous variable $\left\{A_{t}\right\}$ and the initial stocks $k_{0}, d_{0}$.

$$
\begin{gathered}
\lambda_{t}=U_{c}\left(c_{t}, h_{t}\right) \\
-U_{h}\left(c_{t}, h_{t}\right)=\lambda_{t} A_{t} F_{h}\left(k_{t}, h_{t}\right) \\
\lambda_{t}\left(1+\Phi^{\prime}\left(k_{t+1}-k_{t}\right)\right)-\kappa \mu_{t}= \\
=\beta\left(c_{t}, h_{t}\right) E_{t} \lambda_{t+1}\left[A_{t+1} F_{k}\left(k_{t+1}, h_{t+1}\right)+1-\delta+\Phi^{\prime}\left(k_{t+2}-k_{t+1}\right)\right] \\
\lambda_{t}-\mu_{t}=\beta\left(c_{t}, h_{t}\right)(1+r) E_{t} \lambda_{t+1} \\
d_{t}=(1+r) d_{t-1}-y_{t}+c_{t}+i_{t}+\Phi\left(k_{t+1}-k_{t}\right) \\
k_{t+1}=i_{t}+(1-\delta) k_{t} \\
y_{t}=A_{t} F\left(k_{t}, h_{t}\right) \\
\mu_{t}\left(d_{t}-\kappa k_{t+1}\right)=0 \\
\theta_{t+1}=\beta\left(c_{t}, h_{t}\right) \theta_{t}
\end{gathered}
$$

\section{Appendix B: A Model with a Debt-Elastic Interest Rate}

\section{B.1 Household's Optimality Conditions}

Each household chooses again sequences of consumption, hours, investment, capital and one-period international bonds, $\left\{c_{t}, h_{t}, i_{t}, k_{t+1}, d_{t+1}\right\}_{t=0}^{\infty}$, so as to maximize the utility function (1) subject to the Eqs. 2-5, the collateral constraint, Eq. 8, and the definition of the endogenous interest rate premium, Eq. 7, in the main text. I use the same functional forms as described in the previous section. The optimality conditions are:

$$
\begin{gathered}
\lambda_{t}=U_{c}\left(c_{t}, h_{t}\right) \\
-U_{c}\left(c_{t}, h_{t}\right)=\lambda_{t} A_{t} F_{h}\left(k_{t}, h_{t}\right) \\
\lambda_{t}\left(1+\Phi^{\prime}\left(k_{t+1}-k_{t}\right)\right)-\kappa \mu_{t}= \\
=\beta E_{t} \lambda_{t+1}\left[\begin{array}{c}
\left.A_{t+1} F_{k}\left(k_{t+1}, h_{t+1}\right)+1-\delta+\Phi^{\prime}\left(k_{t+2}-k_{t+1}\right)\right] \\
\lambda_{t}-\mu_{t}=\beta\left(1+r_{t}\right) E_{t} \lambda_{t+1}
\end{array}\right.
\end{gathered}
$$




\section{B.2 Macroeconomic Equilibrium}

I solve for a symmetric equilibrium in which all households are alike ex post. Thus, in equilibrium the individual and aggregate variables are identical:

$$
d_{t}=\tilde{d}_{t}
$$

The equilibrium system can be summarized by the following 9 equations in 9 endogenous variables $\left\{c_{t}, h_{t}, i_{t}, k_{t+1}, d_{t}, r_{t}, \lambda_{t}, \mu_{t}, y_{t}\right\}_{t=0}^{\infty}$, given the exogenous variable $\left\{A_{t}\right\}$ and the initial stocks $k_{0}, d_{0}$.

$$
\begin{gathered}
\lambda_{t}=U_{c}\left(c_{t}, h_{t}\right) \\
-U_{c}\left(c_{t}, h_{t}\right)=\lambda_{t} A_{t} F_{h}\left(k_{t}, h_{t}\right) \\
\lambda_{t}\left(1+\Phi^{\prime}\left(k_{t+1}-k_{t}\right)\right)-\kappa \mu_{t}= \\
\beta E_{t} \lambda_{t+1}\left[A_{t+1} F_{k}\left(k_{t+1}, h_{t+1}\right)+1-\delta+\Phi^{\prime}\left(k_{t+2}-k_{t+1}\right)\right] \\
\lambda_{t}-\mu_{t}=\beta\left(1+r_{t}\right) E_{t} \lambda_{t+1} \\
\left.d_{t-1}\right) d_{t-1}-y_{t}+c_{t}+i_{t}+\Phi\left(k_{t+1}-k_{t}\right) \\
k_{t+1}=i_{t}+(1-\delta) k_{t} \\
y_{t}=A_{t} F\left(k_{t}, h_{t}\right) \\
\mu_{t}\left(d_{t}-\kappa k_{t+1}\right)=0 \\
\end{gathered}
$$

\section{Appendix C: Transition Dynamics Without Collateral Constraints}

In this Appendix I plot the transition dynamics of the frictionless EDF and DEIR models, driven by a temporary one-standard-deviation negative TFP shock. Inspection of the IRFs imply that, absent collateral constraints, the two models yield identical dynamics. 

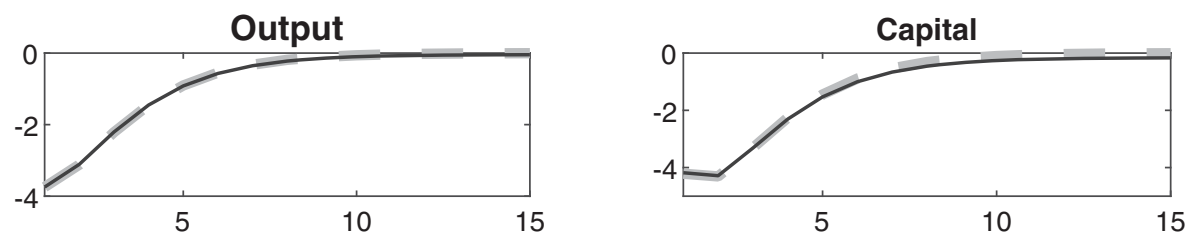

Investment
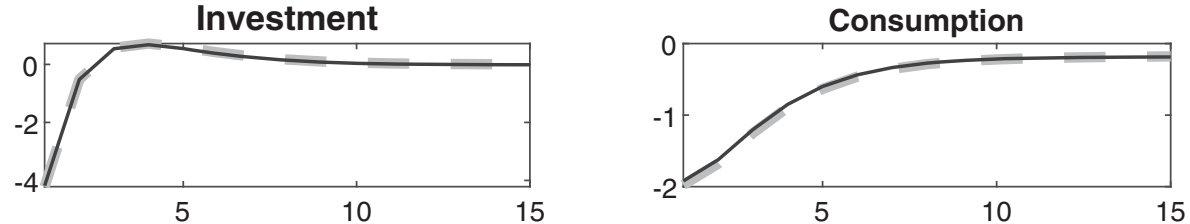

Hours

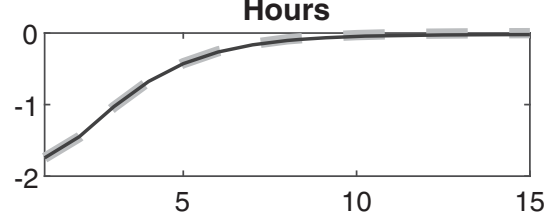

Trade Balance/GDP

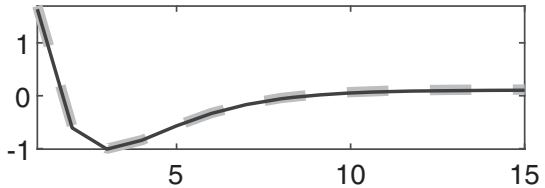

Current Account/GDP
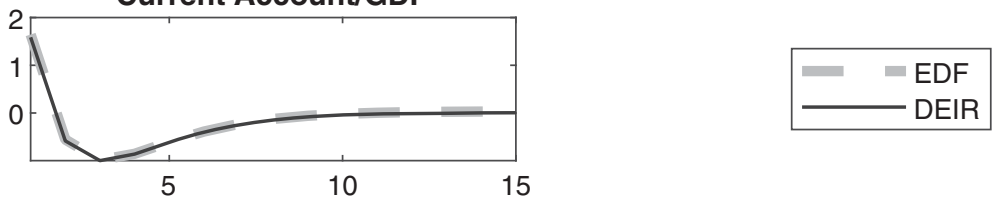

Fig. 3 Effects of a unit negative TFP shock without collateral constraints in \% deviations from the steady state

\section{References}

Aiyagari SR, Gertler M (1999) “Overreaction” asset prices in general equilibrium. Rev Econ Dyn 2(1):3-35

Calvo GA (1998) Capital flows and capital market crises: the simply analytics of sudden stops. J Appl Econ 1:35-54

Guerrieri L, Iacoviello M (2015) Occbin: A toolkit to solve models with occasionally binding constraints easily. J Monet Econ 70:22-38

Kiyotaki N, Moore JH (1997) Credit Cycles. J Polit Econ 105(2):211-248

Kim SH, Kose A (2003) Dynamics of open economy business cycle models: understanding the role of the discount factor. Macroecon Dyn 7(2):263-290

Korinek A, Mendoza GE (2014) From sudden stops to fisherian deflation: quantitative theory and policy. Ann Rev Econ Ann Rev 6:299-332

Lorenzoni G (2014) International financial crises. Handb Int Econ 4:689-740

Mendoza EG (1991) Real business cycles in a small-open economy. Am Econ Rev 81:797-818

Mendoza EG (2002) Credit, Prices, and Crashes: Business Cycles with a Sudden Stop. In: Frankel JA, Edwards S (eds) Preventing Currency Crises in Emerging Markets. University of Chicago Press, Chicago, pp 335-392

Mendoza EG (2010) Sudden stops, financial crises and leverage. Am Econ Rev 100(5):1941-1966

Philippopoulos A, Varthalitis P, Vassilatos V (2017) Fiscal consolidation and its cross-country effects. J Econ Dyn Control 83:55-106

Schmitt-Grohé S, Uribe M (2003) Closing small open economy models. J Int Econ 61:163-185 
Uribe M, Yue VZ (2006) Country spreads and emerging countries: who drives whom? J Int Econ 69(1):6-36 Uribe M, Schmitt-Grohé S (2017) Open economy macroeconomics. Princeton University Press, Princeton Wallace N (1981) A Modigliani-Miller theorem for Open-Market operations. Am Econ Rev 71(3):267-274 Walsh CE (2017) Monetary theory and policy. MIT Press, Cambridge

Publisher's Note Springer Nature remains neutral with regard to jurisdictional claims in published maps and institutional affiliations. 